\title{
All-cause and cause specific mortality in a cohort of 20000 construction workers; results from a 10 year follow up
}

\author{
V Arndt, D Rothenbacher, U Daniel, B Zschenderlein, S Schuberth, H Brenner
}

Occup Environ Med 2004;61:419-425. doi: 10.1136/oem.2003.008680

See end of article for authors' affiliations

.....................

Correspondence to: Dr V Arndt, German Centre for Research on Ageing (DZFA),

Department of

Epidemiology, Bergheimer

Strasse 20, D-69115

Heidelberg, Germany;

arndt@dzfa.

uni-heidelberg.de

Accepted

28 November 2003
Background: Construction workers are potentially exposed to many health hazards, including human carcinogens such as asbestos, silica, and other so-called "bystander" exposures from shared work places. The construction industry is also a high risk trade with respect to accidents.

Methods: A total of 19943 male employees from the German construction industry who underwent occupational health examinations between 1986 and 1992 were followed up until 1999/2000.

Results: A total of 818 deaths occurred during the 10 year follow up (SMR $0.71 ; 95 \% \mathrm{Cl} 0.66$ to 0.76 ). Among those were 299 deaths due to cancer (SMR 0.89; $95 \% \mathrm{Cl} 0.79$ to 1.00 ) and 312 deaths due to cardiovascular diseases (SMR 0.59; $95 \% \mathrm{Cl} 0.51$ to 0.68). Increased risk of mortality was found for nontransport accidents (SMR $1.61 ; 95 \% \mathrm{Cl} 1.15$ to 2.27), especially due to falls (SMR $1.87 ; 95 \% \mathrm{Cl} 1.18$ to 2.92) and being struck by falling objects (SMR 1.90; $95 \% \mathrm{Cl} 0.88$ to 3.64). Excess mortality due to nontransport accidents was highest among labourers and young and middle-aged workers. Risk of getting killed by falling objects was especially high for foreign workers (SMR 4.28; 95\% Cl 1.17 to 11.01 ) and labourers (SMR 6.01; 95\% Cl 1.63 to 15.29).

Conclusion: Fatal injuries due to falls and being struck by falling objects pose particular health hazards among construction workers. Further efforts are necessary to reduce the number of fatal accidents and should address young and middle-aged, semi-skilled and foreign workers, in particular. The lower than expected cancer mortality deserves careful interpretation and futher follow up of the cohort.
$\Lambda$ lthough the number of construction workers has declined in recent years, the construction industry is still one of the largest industries in Germany with approximately 2 million workers employed. ${ }^{1}$ The structural characteristics of the construction industry with large numbers of relatively small companies, multi-employer worksites, and a highly mobile workforce ${ }^{2}$ pose challenges in the field of occupational safety and occupational health surveillance.

Construction workers are potentially exposed to asbestos, silica, other dusts, organic solvents, and other chemicals, but also to noise and vibrations ${ }^{3}$ and to "bystander exposures" present in shared work spaces. ${ }^{4}$ In addition, the construction industry is also a high risk trade with respect to accidents, and the construction industry accounts for the largest numbers of fatal occupational injuries in many countries. ${ }^{5-8}$

Although there is some epidemiological literature in this field, the relations between mortality among construction workers and specific hazards are not well understood. ${ }^{3}$ Several proportionate mortality ratio (PMR) studies indicate an increase in risk of cancer mortality among construction workers. ${ }^{4}{ }^{10}$ For example, increased site specific risks of cancer associated with skilled construction trades have been reported for bone cancer, kidney cancer, nasal cancer, scrotal cancer, lung cancer, rectal cancer, and acute myeloid leukaemia. ${ }^{410}$ In contrast, standardised mortality ratio (SMR) studies comparing construction workers with the general population have reported a decreased risk of cancer $^{11}{ }^{12}$ and all-cause mortality. ${ }^{31-14}$ Some of the discrepancy between SMR and PMR studies is likely to be due to a healthy worker effect, but differences in exposure or background cancer risk might also be discussed.

In this context, more detailed analyses regarding work related and socioeconomic factors, which have not been included in most pertinent studies, would be of major interest. Such data have been collected in a cohort study initiated by our group a number of years ago. In a previous report from this study, ${ }^{15}$ we examined mortality and morbidity among 5000 construction workers over a five year period; we found a significant increase in risk of permanent work incapacity and a tendency towards an increased risk of all-cause mortality for construction workers in comparison to a white collar control group. During the past few years, we were able to enlarge the cohort up to 20000 workers and to expand the follow up period to 10 years. In this paper, we present the results on all-cause and cause specific SMR analyses with respect to work related (job title, years in construction industry) and socioeconomic (age, nationality) factors.

\section{MATERIAL AND METHODS \\ Study population}

The baseline study population comprised all construction workers, aged 25-64 years who were working in one of six job groups (plumbers, carpenters, painters, plasterers, bricklayers, and unskilled workers/labourers) and who participated in a health examination by the Institution for Statutory Accident Insurance and Prevention in the building trade in Baden-Württemberg (a state with about 10 million people in the south of Germany) between 1 August 1986 and 31 December 1992. As over $95 \%$ of all construction workers in Germany are men, ${ }^{1}$ our study is limited to male workers. The baseline health examination is part of the routine occupational health surveillance and includes occupational and medical history, a physical examination, pulmonary function test, test of visual acuity, audiometry, and blood and serum analysis. The examination is based on legislation on health and safety at work in Germany ("Arbeitssicherheitgesetz") and is offered to all construction workers. Participation is

Abbreviations: PMR, proportionate mortality ratio; SMR, standardised mortality ratio 
Main messages

- All-cause mortality of construction workers was lower than unity compared with the general population (SMR $0.71)$

- Excess mortality was observed for pneumoconiosis (SMR 2.30) and for non-transport accidents such as falls (SMR 1.58) and being struck by falling objects (SMR 1.90).

- Relative risk of fatal non-transport accidents was highest among young and middle-aged workers, workers of foreign nationality, and labourers.

voluntary but over $75 \%$ of all invited employees have participated in the medical examination during the period of recruitment. In total, the study sample comprised 19943 workers, who fulfilled the above mentioned inclusion criteria and who were eligible for follow up.

\section{Follow up}

In the absence of a national death index in Germany, residents' registration offices were contacted to obtain most recent information on vital status of all cohort members between October 1998 and February 2000. If necessary (for example, in the case of study participants who have moved within Germany during the follow up), subsequent residents' registration offices were contacted until the latest information on vital status was obtained. Workers who moved to a foreign country $(n=719,3.6 \%)$ or with unknown place of residence $(n=159,0.8 \%)$ were censored with date of last known residence. No follow up information was available for 116 members of the baseline population $(0.6 \%)$, yielding a final study population of 19827 men. In case of deceased study participants, death certificates were obtained from the regional public health departments, and cause of death was abstracted from each death certificate by two trained physicians (VA, UD) and classified according to the 9th revision of the International Classification of Diseases (ICD9). Discrepant indexing was resolved by a professional nosologist.

\section{Statistical methods}

Standardised mortality ratios (SMR) for all-cause and cause specific mortality were calculated with the SAS statistical software package ${ }^{16}$ using age (25-29, 30-34 .. 70-79), sex, and calendar year specific mortality data from the BadenWürttemberg general population (comprising citizens of German and non-German nationality) as reference. Exact 95\% confidence limits were calculated with the SISA software. ${ }^{17}$ In case of $\geqslant 15$ observed deaths, the Poisson process approximation ${ }^{18}$ was employed.

Causes of interest included all cancer (ICD-9: 140-208), cancer of the oral cavity and pharynx (ICD-9: 140-149), cancer of the digestive system (ICD-9: 150-159), cancer of the respiratory system (ICD-9: 160-165), diseases of the circulatory system (ICD-9: 390-459), ischaemic heart disease (ICD-9: 410-414), heart failure and other forms of heart disease (ICD-9: 420-429), cerebrovascular disease (ICD-9: 430-438), diseases of arteries, arterioles, and capillaries (ICD9: 440-448), diseases of the respiratory system (ICD-9: 460519), chronic obstructive pulmonary disease and allied conditions (ICD-9: 490-496), pneumoconiosis and other lung diseases related to external agents (ICD-9: 500-508), diseases of the digestive system (ICD-9: 520-579), injury and poisoning (ICD-9: 800-999), all accidents (E800-E869, E880-E929), transport accidents (E800-E848), non-transport

\section{Policy implications}

- The construction industry is a high risk trade with respect to non-transport accidents.

- Variations in fatal injury rate across different age, occupational, and ethnic groups indicate the potential for improving occupational safety and health.

- Further efforts to reduce the number of fatal accidents are necessary and should in particular include younger, semi-skilled, and foreign workers.

accidents (E850-E869, E880-E929), falls (E880-E929), being struck by falling objects (E916-E928), and suicide (E950E959). Criteria for the selection of these specific causes were findings from previous reports and the number of expected cases. SMRs were calculated for the total cohort but also for each occupational group (to detect potential job specific mortality patterns), for different age groups (to detect age specific differences), by nationality, and by duration of employment.

Information on cause of death could be obtained for $84.8 \%$ of all deceased. Missing death certificates arise from the fact that death certificates have to be stored at the regional state's health offices for five years only in Baden-Württemberg and may be destroyed thereafter. Since this missing information on cause specific deaths affects only the cause specific mortality of our cohort members and not the official mortality rates from the general population, we employed the method described by Rittgen and Becker ${ }^{19}$ to adjust for missing death certificates. Under the (quite plausible) assumption that the availability of the cause of death certificate is not related to the exposure under consideration

Table 1 Characteristics of the study population at baseline examination

\begin{tabular}{|c|c|c|}
\hline & $\mathbf{n}$ & $\%$ \\
\hline \multicolumn{3}{|l|}{ Occupation } \\
\hline Plumbers & 2843 & 14.3 \\
\hline Carpenters & 2667 & 13.5 \\
\hline Painters & 2999 & 15.1 \\
\hline Plasterers & 2040 & 10.3 \\
\hline Bricklayers & 6330 & 31.9 \\
\hline Labourers & 2948 & 14.9 \\
\hline \multicolumn{3}{|c|}{ Age at baseline examination } \\
\hline $25-34$ years & 6018 & 30.4 \\
\hline $35-44$ years & 4141 & 20.9 \\
\hline $45-54$ years & 6529 & 32.9 \\
\hline $55-64$ years & 3139 & 15.8 \\
\hline Mean (SD) & \multicolumn{2}{|c|}{$42.6(10.8)$ years } \\
\hline \multicolumn{3}{|l|}{ Nationality } \\
\hline German & 14725 & 74.3 \\
\hline Former Yugoslavia & 1814 & 9.2 \\
\hline Italian & 1359 & 6.9 \\
\hline Turkish & 1277 & 6.4 \\
\hline Other & 652 & 3.3 \\
\hline \multicolumn{3}{|c|}{$\begin{array}{l}\text { Duration of employment in construction } \\
\text { industry* }\end{array}$} \\
\hline$<15$ years & 6499 & 36.7 \\
\hline $15-29$ years & 6359 & 35.9 \\
\hline$\geqslant 30$ years & 4843 & 27.4 \\
\hline Mean (SD) & \multicolumn{2}{|c|}{$20.6(11.8)$ years } \\
\hline \multicolumn{3}{|l|}{ Smoking status $†$} \\
\hline Current smoker & 9559 & 57.3 \\
\hline Former smoker & 3014 & 18.1 \\
\hline Never smoker & 4117 & 24.7 \\
\hline Total & 19827 & 100.0 \\
\hline
\end{tabular}


Table 2 SMR of all-cause and cause specific mortality within total cohort

\begin{tabular}{|c|c|c|c|}
\hline Cause of death (ICD-9) & Observed & Expected* & SMR $(95 \% \mathrm{Cl})^{*}$ \\
\hline Cancer (ICD 140-208) & 299 & 335 & $0.89(0.79$ to 1.00$)$ \\
\hline Cancer of the oral cavity and pharynx (ICD 140-149) & 23 & 26.8 & $0.86(0.54$ to 1.29$)$ \\
\hline Cancer of the digestive system (ICD 150-159) & 99 & 112 & $0.89(0.72$ to 1.08$)$ \\
\hline Cancer of the respiratory system (ICD 160-165) & 100 & 99 & $1.01(0.82$ to 1.22 \\
\hline Circulatory system (ICD 390-459) & 185 & 312 & $0.59(0.51$ to 0.68$)$ \\
\hline Ischaemic heart disease (ICD 410-414) & 109 & 178 & $0.61(0.50$ to 0.74$)$ \\
\hline Heart failure, other heart disease (ICD 420-429) & 29 & 52 & $0.55(0.37$ to 0.80$)$ \\
\hline Cerebrovascular disease (ICD 430-438) & 22 & 49 & $0.45(0.28$ to 0.68$)$ \\
\hline Diseases of arteries, arterioles, and capillaries (ICD 440-448) & 10 & 11 & $0.88(0.44$ to 1.67$)$ \\
\hline Respiratory system (ICD 460-519) & 23 & 38 & $0.60(0.38$ to 0.90$)$ \\
\hline $\begin{array}{l}\text { Chronic obstructive pulmonary disease and allied conditions } \\
\text { (ICD 490-496) }\end{array}$ & 14 & 25 & $0.55(0.31$ to 0.94$)$ \\
\hline $\begin{array}{l}\text { Pneumoconiosis and other lung diseases related to external } \\
\text { agents (ICD 500-508) }\end{array}$ & 3 & 1.3 & $2.30(0.48$ to 6.74$)$ \\
\hline Digestive system (ICD 520-579) & 63 & 90 & $0.70(0.54$ to 0.90$)$ \\
\hline Injury and poisoning (ICD 800-999) & 86 & 95 & $0.90(0.72$ to 1.12$)$ \\
\hline Accidents (E800-E869, E880-E929) & 52 & 44 & $1.18(0.88$ to 1.54$)$ \\
\hline Transport accidents (E800-E848) & 16 & 22 & $0.73(0.42$ to 1.18$)$ \\
\hline Non-transport accidents (E850-E869, E880-E929) & 36 & 22 & $1.61(1.15$ to 2.27$)$ \\
\hline Falls (E880-E888) & 21 & 11 & $1.87(1.18$ to 2.92$)$ \\
\hline Struck by falling objects (E916-E928) & 9 & 4.7 & $1.90(0.88$ to 3.64$)$ \\
\hline Suicide (E950-E959) & 27 & 46 & $0.59(0.39$ to 0.85$)$ \\
\hline All deaths (ICD 001-999) & 818 & 1150 & $0.71(0.66$ to 0.76$)$ \\
\hline
\end{tabular}

(for example, working in the construction industry), it can be easily shown that the true but unknown number of cause specific deaths can be derived from the known number of deaths from this cause divided by the proportion of all known causes of death among all deceased participants.

\section{RESULTS}

Table 1 shows characteristics of the study population at baseline examination. Bricklayers represented the largest professional group, with almost one third of the total study population. Mean age of the study population at baseline was 42.6 years, with highest numbers in the age groups 25-34 years and $45-54$ years. Almost $75 \%$ of the cohort members were of German nationality, followed by migrants (or their descendants) from former Yugoslavia, Italy, and Turkey. On average, cohort members have worked over 20 years in the building trade. Exposure to asbestos and to silica was reported by $7.5 \%$ and $2.4 \%$, respectively (data not shown). Data on smoking were available for $84.2 \%$. Among these, $57.3 \%$ classified themselves at smokers. These data indicate that the smoking prevalence in the sample of construction worker was much higher than in the general population of Germany during the same period, when approximately 35$39 \%$ of all males were smokers. ${ }^{20}$

During the follow up period 818 men died. Death certificates were available for $694(84.8 \%)$ of the deceased. Among these, cancer $(43.1 \%)$ and cardiovascular disease $(26.7 \%)$ were the most common causes of death. The third leading cause of death was injuries and poisoning (12.4\%). Injuries and poisoning were the leading causes of death among those construction workers who died aged 25-44 years, and accounted for almost one third of all fatalities in this age group. Digestives diseases (63 cases) accounted for $9.1 \%$ of all deaths across all ages and were mainly related to liver cirrhosis ( 58 cases; data not shown).

Table 2 shows standardised all-cause and cause specific mortality ratios for the total cohort. With respect to all-cause mortality, this cohort of construction workers experienced a $29 \%$ lower mortality than males from the general population
(SMR 0.71). Lower than expected mortality was observed for most causes of death, in particular, mortality due to cardiovascular diseases (SMR 0.59) and cancer (SMR 0.89). Cancers of the gastrointestinal system and the respiratory system accounted for one third of cancer deaths each. For cancer of the respiratory system, the number of observed was very close to the number of expected cases (SMR 1.01) despite a high smoking prevalence in the cohort and the potential for exposure to asbestos and silica dust. No excess cancer mortality was observed for other major tumour sites.

There was no excess mortality with respect to diseases of the respiratory system or to diseases of the digestive system. However, there was some (non-significant) excess mortality due to pneumoconiosis (SMR 2.30), but the number of cases was very small (three cases).

Injury and poisoning were responsible for 86 deaths. Among those were 16 transport accidents, 36 non-transport accidents, and 27 suicides. Excess mortality was limited to non-transport accidents (SMR 1.61) and mainly due to falls (21 cases; SMR 1.87) and being struck by falling objects (9 cases; SMR 1.90). Increase in risk was not observed for transport accidents ( 16 cases; SMR 0.73 ) or for suicides (27 cases; SMR 0.59).

Further in-depth analysis with stratifying the cohort by age, nationality, occupation, and duration of employment did not reveal any increased risk with respect to total mortality and cancer, diseases of the circulatory, respiratory, or the digestive system as cause of death (table 3) with the exception of an increased SMR of 1.51 (95\% CI 1.00 to 2.30) for cancer mortality among the 25-44 year olds. When we stratified the sample into workers of German and nonGerman nationality, lower than expected mortality was observed for both groups, but workers of non-German nationality showed a statistically significant lower all-cause mortality than German worker $(p=0.01)$. Similar differences by nationality were found within the cause specific analysis. Stratification by profession revealed that mortality was highest among labourers for all-cause mortality and for mortality from most causes specifically addressed in this 


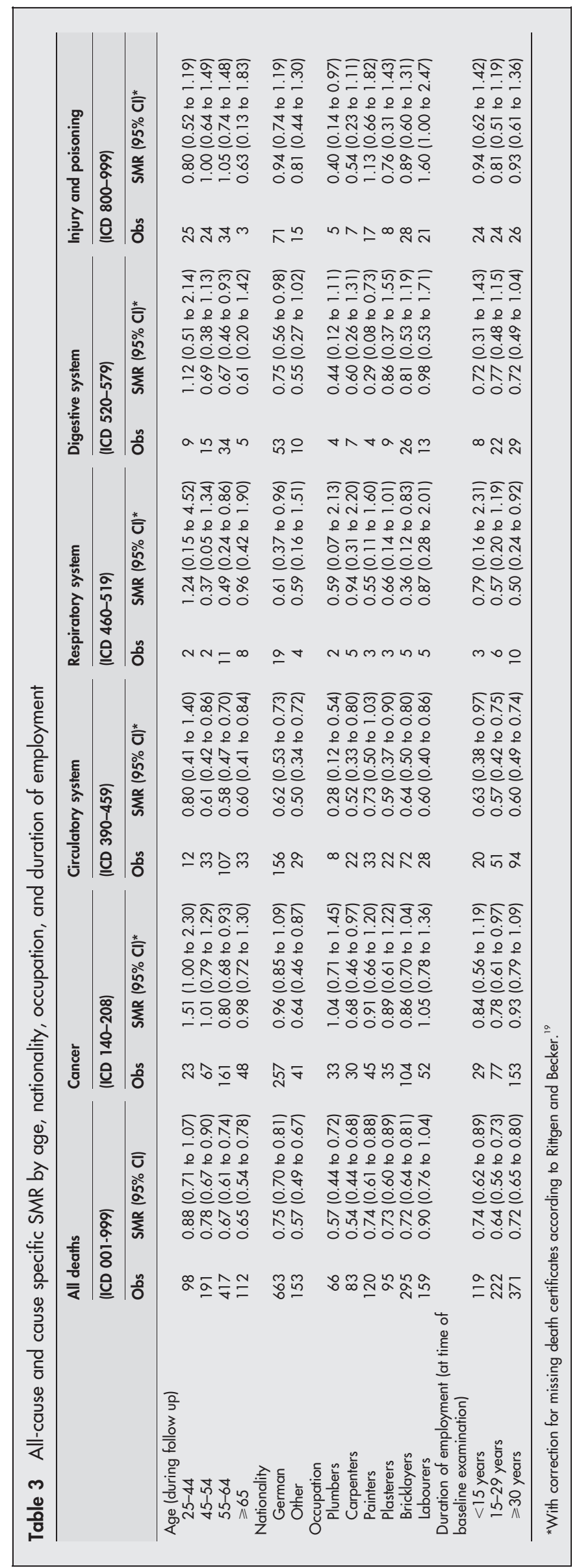


Table 4 SMR of non-transport accidents by age, nationality, occupation, and duration of employment

\begin{tabular}{|c|c|c|c|c|c|c|c|c|c|}
\hline & \multirow{2}{*}{\multicolumn{3}{|c|}{$\begin{array}{l}\text { All non-transport accidents } \\
\text { (E850-E869, E880-E929) }\end{array}$}} & \multirow{2}{*}{\multicolumn{3}{|c|}{$\begin{array}{l}\text { Falls } \\
\text { (E880-E888) }\end{array}$}} & \multirow{2}{*}{\multicolumn{3}{|c|}{$\begin{array}{l}\text { Struck by falling objects } \\
\text { (E916-E928) }\end{array}$}} \\
\hline & & & & & & & & & \\
\hline & Obs & Exp* & SMR $(95 \% \mathrm{Cl})^{*}$ & Obs & Exp* & SMR $(95 \% \mathrm{Cl})^{*}$ & Obs & Exp* & SMR $(95 \% \mathrm{Cl})^{*}$ \\
\hline \multicolumn{10}{|c|}{ Age (during follow up) } \\
\hline $25-44$ & 9 & 4.7 & $1.93(0.88$ to 3.67$)$ & 4 & 1.6 & 2.46 (0.67 to 6.28$)$ & 4 & 1.3 & 3.05 (0.83 to 7.82 ) \\
\hline $45-54$ & 13 & 5.6 & 2.33 (1.24 to 3.98$)$ & 8 & 2.8 & 2.91 (1.26 to 5.73 ) & 4 & 1.2 & $3.22(0.88$ to 8.26$)$ \\
\hline $55-64$ & 14 & 9.8 & $1.43(0.78$ to 2.40$)$ & 9 & 5.4 & $1.66(0.76$ to 3.15$)$ & 1 & 1.8 & $0.55(0.01$ to 3.06$)$ \\
\hline$\geqslant 65$ & 0 & 2.0 & $0.00(0.00$ to 1.84$)$ & 0 & 1.3 & 0.00 (0.00 to 2.84$)$ & 0 & 0.2 & $0.00(0.00$ to 18.44$)$ \\
\hline \multicolumn{10}{|l|}{ Nationality } \\
\hline German & 28 & 17.5 & $1.60(1.06$ to 2.31$)$ & 18 & 8.8 & 2.04 (1.21 to 3.23 ) & 5 & 3.7 & $1.35(0.44$ to 3.15$)$ \\
\hline Other & 8 & 4.5 & $1.79(0.77$ to 3.53$)$ & 3 & 2.3 & $1.32(0.27$ to 3.86$)$ & 4 & 0.9 & $4.28(1.17$ to 11.01$)$ \\
\hline \multicolumn{10}{|l|}{ Occupation } \\
\hline Plumbers & 2 & 2.6 & 0.76 (0.09 to 2.75$)$ & 2 & 1.2 & 1.61 (0.20 to 5.83$)$ & 0 & 0.6 & $0.00(0.00$ to 6.15$)$ \\
\hline Carpenters & 3 & 2.9 & $1.02(0.21$ to 2.98$)$ & 2 & 1.5 & 1.35 (0.16 to 4.88 ) & 1 & 0.6 & $1.60(0.04$ to 8.84$)$ \\
\hline Painters & 7 & 3.4 & $2.04(0.82$ to 4.21$)$ & 4 & 1.7 & $2.33(0.63$ to 5.95$)$ & 0 & 0.7 & $0.00(0.00$ to 5.27$)$ \\
\hline Plasterers & 4 & 2.5 & $1.58(0.43$ to 4.05$)$ & 3 & 1.3 & $2.32(0.48$ to 6.80$)$ & 1 & 0.5 & $1.88(0.05$ to 10.51$)$ \\
\hline Bricklayers & 12 & 7.6 & $1.58(0.82$ to 2.76$)$ & 7 & 3.9 & $1.79(0.72$ to 3.69$)$ & 3 & 1.6 & $1.89(0.39$ to 5.51$)$ \\
\hline Labourers & 8 & 3.2 & 2.52 (1.09 to 4.97$)$ & 3 & 1.6 & $1.84(0.38$ to 5.38$)$ & 4 & 0.7 & $6.01(1.63$ to 15.29$)$ \\
\hline \multicolumn{10}{|c|}{$\begin{array}{l}\text { Duration of employment (at } \\
\text { time of baseline } \\
\text { examination) }\end{array}$} \\
\hline$<15$ years & 4 & 4.3 & $0.92(0.25$ to 2.35$)$ & 3 & 1.8 & $1.67(0.34$ to 4.87$)$ & 1 & 1.1 & $0.92(0.02$ to 5.11$)$ \\
\hline $15-29$ years & 13 & 7.1 & $1.84(0.98$ to 3.15$)$ & 6 & 3.6 & $1.68(0.62$ to 3.66$)$ & 3 & 1.5 & $2.05(0.42$ to 6.00$)$ \\
\hline$\geqslant 30$ years & 11 & 8.2 & $1.34(0.68$ to 2.40$)$ & 7 & 4.6 & $1.53(0.61$ to 3.15$)$ & 3 & 1.6 & $1.92(0.40$ to 5.62$)$ \\
\hline
\end{tabular}

analysis. In particular, deaths due to external causes showed an SMR of 1.60 (95\% CI 1.00 to 2.47). Finally, there was no clear association between mortality and duration of employment, either for all-cause mortality or for any specific cause. Furthermore, analysis by latency (with 20, 30, and 40 years lag time) revealed no evidence for an increased risk either for cancer or for all-cause mortality (data not shown).

Table 4 depicts some details of non-transport accidents which represent an area of concern within this cohort. Relative risk of non-transport accidents was highest for workers below age 55 and labourers. Risk of fatal falls was increased for all professions in this cohort compared with general population norms, whereas being struck by falling objects seemed to represent a particular hazard for labourers (SMR 6.01) and non-German workers (SMR 4.28).

\section{DISCUSSION}

Overall, construction workers in the German building trade experience higher risk of dying due to non-transport accidents and pneumoconiosis, but seem to experience lower all-cause mortality and mortality due to chronic conditions such as cancer and cardiovascular disease when compared with males from the general population. The lower than expected mortality might be surprising given the working conditions including potential exposure to carcinogens, physically demanding jobs, climatic conditions, heavy lifting, noise, vibration, and lifestyle factors such as cigarette smoking and heavy alcohol consumption ${ }^{21}$ and deserves careful discussion.

Excess mortality due to accidents seems to be limited to non-transport accidents in this cohort and does not apply to transport accidents as reported by Ore and Fosbroke, ${ }^{22}$ who observed that construction workers were twice as likely to be killed by a motor vehicle as the average worker. This difference might be explained by the fact that our cohort was recruited within the building trade and not from road construction where transportation accidents pose a major problem.

Almost 20\% of all work related injuries in Germany and over $23 \%$ of all work related fatal injuries occur in the construction industry. ${ }^{8}$ The annual injury rate (non-fatal and fatal accidents) of 82 per 1000 construction workers is about
2.5 times the average rate of 34.5 per 1000 in all trade industries. ${ }^{8}$ Similar figures have been reported from the $\mathrm{USA}^{56}$ and the UK. ${ }^{7}$ We observed a statistically significant excess mortality in this cohort for non-transport accidents, such as falls and being struck by falling objects. Other studies have not established whether older or younger workers are at higher risk of injuries. In several studies older workers were more likely to suffer work related injuries, ${ }^{23-26}$ whereas other reports $^{27-29}$ have suggested that younger workers are at increased risk. In our study, young and middle-aged men, labourers, and workers of foreign nationality seemed to represent high risk groups for fatal accidents.

The dangers of construction sites are well known and high rates of traumatic fatalities have been previously documented, ${ }^{30}$ specifically falls from ladders or scaffolds, falls from or out of buildings or structures, and electrocutions. ${ }^{10}$ Carpenters experienced the lowest risk for fatal falls in this cohort although they work predominantly with a risk of falling. This apparent discrepancy might be explained by their experience and awareness of the risks and safety guidelines while working on roofs, ladders, or scaffolds/platforms. In contrast, non-awareness of safety guidelines might be a reason for the high fatality rates due to being struck by falling objects among foreign workers and labourers. However, the numbers of fatal falls within each job category were very small and the findings deserve confirmation from larger samples.

The low mortality with respect to all-cause mortality, cancer, and cardiovascular disease is likely to reflect a "healthy worker survivor effect", a continuing selection process in that those who remain employed tend to be healthier than those who leave employment. ${ }^{31}$ Previous studies among construction workers using SMR techniques revealed similar findings regarding all-cause and cancer specific mortality. For example Engholm and Englund ${ }^{11} 12$ reported an SMR of 0.74 for all-cause mortality and of 0.88 for cancer mortality among construction workers in Sweden when compared with the general population. Both figures are very close to the results derived from our cohort.

Although our study subjects had been working in the construction industry for over 20 years on average (at baseline) and followed over an 8-14 years period, the current 
latency period might be too short for the development of cancer or other chronic health effects. The potential of effect dilution caused by too broad and non-specific disease categories must also be considered. For example, in Engholm and Englund's study ${ }^{11}{ }^{12}$ excess of cancer mortality was limited to specific sites and to specific occupational subgroups such as concrete workers, plumbers, insulators, rock workers, and sheet metal workers who might more likely be exposed to asbestos and silica. Similarly, a recent case-control study from Germany ${ }^{32}$ reported a statistically significant increased lung cancer risk for specific professional groups from the construction industry including bricklayers, carpenters, road construction workers, painters, and lacquerers. In our study, increased cancer mortality was observed for younger workers, and the upper levels of $95 \%$ confidence intervals exceeded 1.0 for each group of cancer looked at in this analysis. Further site and age specific analysis with an extended follow up period might be warranted.

In our study, migrants from other countries experienced a $25 \%$ lower mortality compared to German construction workers. This phenomenon may be due to either a healthy migrant effect caused by a selection process in the 1960s when workers from Southern European countries with good physical health were hired to work in Germany, or an "unhealthy re-migration effect". ${ }^{33}$

Our data indicate that, among construction workers, labourers experience the highest mortality with respect to several causes of death. Similarly, a Finnish study ${ }^{34}$ reported that semiskilled construction workers had the highest mortality rate almost independent of the cause of death, but differences to other professional groups were highest with respect to accidents. A recent study from the USA also indicates that labourers experience the highest rates of fatal occupational injuries. ${ }^{25}$

A major limitation inherent in studies which rely on voluntary participation is the potential for bias due to nonrepresentative self selection of the study members. Results from the Swedish construction industry preventive health programme indicated that non-participants of occupational safety and health screening programmes had mortality rates $72 \%$ higher than those of participants. ${ }^{35}$ The differences seemed to be especially noteworthy for features associated with poor health behaviour such as alcoholism and liver cirrhosis. In this study, we were not able to obtain further information from non-participants. Therefore we cannot rule out that the observed mortality of study participants is somewhat underestimating the true mortality of the source population, although over $75 \%$ of all eligible employees participated in the baseline examination. Similarly, we are also concerned about those who left the construction industry for health reasons before the baseline examination took place. Another limitation inherent in mortality studies is the fact that hazards that cause substantial morbidity (but impose a low risk of mortality) such as hearing loss, and musculoskeletal and skin disorders cannot be studied but nevertheless pose major challenges for occupational health and also deserve close attention. So far, we have only been able to look at mortality data, which are often less accurate than morbidity data. Information of cause of death was missing for $15 \%$ of all deceased persons. Although the adjustment by Rittgen and Becker works well for the more frequent causes of death, estimates for rare causes of deaths (such as site specific cancers) might be less accurate. Further follow up with respect to mortality and morbidity should help to resolve some of the open issues.

Despite its limitations, our study indicates that the construction industry is still a high risk trade with respect to non-transport accidents with a large number of injuries, which are in general primarily preventable. The observed variations in fatal injury rates with respect to age, nationality, and occupation indicate the potential for further targeting of occupational safety and health measures. Further efforts to reduce the number of fatal accidents are necessary and should address young and middle-aged, semi-skilled, and foreign workers, in particular.

\section{Authors' affiliations}

V Arndt, D Rothenbacher, H Brenner, German Centre for Research on Ageing, Department of Epidemiology, Bergheimer Strasse 20, D-691 15 Heidelberg, Germany

U Daniel, B Zschenderlein, S Schuberth, Occupational Health Service, Workmen's Compensation Board for Construction Workers Württemberg, D-71029 Böblingen, Germany

Financial support: This study was partly supported by the Association of the Workmen's Compensation Board for Construction Workers, Germany

\section{REFERENCES}

1 Bundesanstalt für Arbeit. Arbeitsmarkt in Zahlen 31 März 2002. Nuremberg, Germany 2002. Available at: http://www.arbeitsamt.de/HST/services/ statistik. Accessed 24 February 2003.

2 Ward EM, Burnett CA, Ruder A, et al. Industries and cancer. Cancer Causes Control 1997;8:356-70.

3 Sun J, Kubota $\mathrm{H}$, Hisanaga $\mathrm{N}$, et al. Mortality among Japanese construction workers in Mie Prefecture. Occup Environ Med 2002:59:512-16.

4 Robinson CF, Halperin WE, Alterman T, et al. Mortality patterns among construction workers in the United States. Occup Med 1995; 10:269-83.

5 Center for Diseases Control, Health, United States, 2001. Health Status and Determinants-Highlights. Available at: http://www.cdc.gov/nchs/ products/pubs/pubd/hus/hestatus.pdf. Accessed 24 February 2003.

6 The Center to Protect Workers Rights, The Construction Chart Book. The US Construction Industry and lts Workers, 2002. Available at: http:// www.cdc.gov/niosh/elcosh/docs/d0100/d000038/contents.html. Accessed 24 February 2003.

7 Health and Safety Commission. Health and Safety Statistics 2000/01. 2001, National Statistics. Available at: http://www.hse.gov.uk/statistics/2001/ hsspt1.pdf. Accessed 24 February 2003.

8 Zentrales Informationssystem der Gesetzlichen Unfallversicherung. Hauptverband der gewerblichen Berufsgenossenschaften, Sankt Augustin, Germany. Available at: http://www.hvbg.de/d/ziguv/info-s/unfall/au/ haeuf.htm. Accessed 24 February 2003.

9 Dong W, Vaughan P, Sullivan K, et al. Mortality study of construction workers in the UK. Int J Epidemiol 1995;24:750-7.

10 Wang E, Dement JM, Lipscomb H. Mortality among North Carolina construction workers, 1988-1994. Appl Occup Environ Hyg 1999;14:45-58.

11 Engholm G, Englund A. Morbidity and mortality patterns in Sweden. Occup Med 1995; 10:261-8.

12 Engholm G, Englund A. Mortality and cancer incidence in various groups of construction workers. Occup Med 1995;10:453-81.

13 Sun J, Shibata E, Hisanaga N, et al. A cohort mortality study of construction workers. Am J Ind Med 1997;32:35-41.

14 Ng TP. Occupational mortality in Hong Kong, 1979-1983. Int J Epidemiol 1988;17:105-10.

15 Arndt V, Rothenbacher $\mathrm{D}$, Brenner $\mathrm{H}$, et al. Older workers in the construction industry: results of a routine health examination and a five year follow up. Occup Environ Med 1996;53:686-91.

16 SAS. SAS Statistical Analysis System. Cary, NC: SAS Institute Inc., 19992001.

17 Uitenbroek DG. SISA Simple Interactive Statistical Analysis. 1997. Available at: http://home.clara.net/sisa/smr.htm. Accessed 19 September 2003.

18 Liddel FDK. Simple exact analysis of the standardised mortality ratio. J Epidemiol Community Health 1984;38:85-8.

19 Rittgen W, Becker N. SMR analysis of historical follow-up studies with missing death certificates. Biometrics 2000;56:1164-9.

20 Junge B, Nagel M. Smoking behavior in Germany [in German]. Gesundheitswesen 1999:61:S121-5.

21 Harford TC, Brooks SD. Cirrhosis mortality and occupation. J Stud Alcohol 1992; 53:463-8

22 Ore T, Fosbroke DE. Motor vehicle fatalities in the United States construction industry. Accid Anal Prev 1997;29:613-26.

23 Lowery JT, Borgerding JA, Zhen B, et al. Risk factors for injury among construction workers at Denver International Airport. Am J Ind Med 1998;34:113-20.

24 Buskin SE, Paulozzi $\amalg$. Fatal injuries in the construction industry in Washington State. Am J Ind Med 1987; 1 1:453-60.

25 Jackson SA, Loomis D. Fatal occupational injuries in the North Carolina construction industry, 1978-1994. Appl Occup Environ Hyg 2002; 17:27-33

26 Kisner SM, Fosbroke DE. Injury hazards in the construction industry. J Occup Med 1994;36:137-43. 
27 Lipscomb HJJK, Dement JM. Workers' compensation claims of union carpenters 1989-1992: Washington state. Appl Occup Environ Hyg $1996 ; 11: 56-63$.

28 Stern FB, Sweeney MH, Ward E. Proportionate mortality among unionized construction ironworkers. Am J Ind Med 1997;31:176-87.

29 Zschenderlein B. The influence of age on the incidence of accidents in the construction industry [in German]. Schriftenreihe Zentralblatt für Arbeitsmedizin. Vol. 16. Heidelberg: Dr Curt Haefner Verlag, 1997.

30 Bell CA, Stout NA, Bender TR, et al. Fatal occupational injuries in the United States, 1980 through 1985. JAMA 1990;263:3047-50.

31 Arrighi HM, Hertz-Picciotto I. The evolving concept of the healthy worker survivor effect. Epidemiology 1994;5: 189-96.
32 Brüske-Hohlfeld I, Möhner M, Pohlabeln H, et al. Occupational lung cancer risk for men in Germany: results from a pooled case-control study. Am J Epidemiol 2000;151:384-95.

33 Razum O, Zeeb H, Akgun HS, et al. Low overall mortality of Turkish residents in Germany persists and extends into a second generation: merely a healthy migrant effect? Trop Med Int Health 1998;3:297-303.

34 Notkola VJ, Martikainen P, Leino PI. Time trends in mortality in forestry and construction workers in Finland 1970-85 and impact of adjustment for socioeconomic variables. J Epidemiol Community Health 1993;47:186-91.

35 Ringen K, Seegal J, Englund A. Safety and health in the construction industry. Annu Rev Public Health 1995; 16:165-88.

\section{$\mathrm{ECHO}$}

\section{Occupational risk factors for hip arthritis}

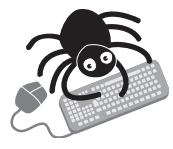

Please visit the Occupational and

Environmental Medicine website [www. occenvmed. com] for a link to the full text of this article.
K nown or suggested risk factors for osteoarthritis of the hip (coxarthrosis) include physical workload, sporting activities, and obesity. Farmers and farm workers may be at particularly high risk and, within farming, tractor driving (especially in a twisted position), working with dairy herds or pigs, milking cows, and working on small farms have all been regarded as possible risk factors. Now a Danish study of four successive cohorts of male workers has provided fresh data about time trends and risks in different socioeconomic and occupational groups.

All employed Danish men aged 20-59 years in January 1981, 1986, 1991, and 1994 were grouped according to main occupation one year previously and followed up for two to five years for hospital admission with hip arthritis. The highest rates of first admission for this cause during 1994-99 were among self employed men and unskilled workers (standardised hospitalisation ratios (SHRs) 140 and 121) and unemployed men (SHR 156). Managers, salaried staff, and skilled workers had relatively low SHRs (56-96). Between 1981 and 1999 the SHR decreased slightly among self employed men and increased slightly among leading salaried staff and skilled and unskilled workers. Between 1981-85 and 1994-97 the SHR remained steady and high (281-286) among self employed farmers and was lower but rising (114-189) among farm employees. Men in agricultural tractor pools had an SHR of 210 in 1981-85 and 183 in 1994-99. Men who had much lower SHRs in 1994-99 included electronics mechanics and servicers (SHR 12), teachers (37), doctors (46) and armed forces (57). High risk occupations included bakers and pastry cooks (SHR 204), waiters and bartenders (204) and machine operators (207).

In recent decades the number of farms and farmers has fallen in Denmark but the number of farm workers has remained the same. Increased SHRs among farm workers might be due to their having taken over tasks previously done by farmers. Specific factors probably associated with increased risk of hip osteoarthritis include heavy lifting, prolonged standing, body vibration, tractor driving, and walking on rough ground.

A Annals of the Rheumatic Diseases 2003;62:1100-1105. 


\section{PostScript}

\section{LETTER}

\section{Can $\delta$-aminolevulinic acid dehydratase 2 allele exert certain protective measures against the neurotoxic effects of lead?}

Recently, there has been a lot of interest regarding $\delta$-aminolevulinic acid dehydratase (ALAD) polymorphism and health effects of inorganic lead. Most of these reports focused on renal effects. ${ }^{12}$ There have been reports on the effects of lead on neurobehavioural function among exposed workers. ${ }^{3}$ As far as we know, only one paper has reported the effects of ALAD polymorphism and neurobehavioural testing. Bellinger et al studied 72 adolescents with high $(>24 \mu \mathrm{g} / \mathrm{g})$ and low $(<8.7 \mu \mathrm{g} / \mathrm{g})$ dentin lead levels. The results suggested that the body burden and effects of lead on neurobehavioural functions were worse among ALADl homozygotes.'

We have carried out a cross-sectional study in 106 male workers exposed to low or moderate levels of inorganic lead in order to investigate the association between ALADl and ALAD2 genotypes and neurobehavioural functions. Blood and urine were collected for each worker to determine the ALAD genotype, blood lead levels, ALAD, and urinary $\delta$ aminolevulinic acid (ALAU). ALADl-1 was the predominant genotype for all three ethnic groups (Chinese, Malays, and Indians) while ALAD2-2 was the rarest. The distribution of ALADl-2 was higher among the Malays (17.5\%) and Indians (15.2\%) compared to the Chinese $(8.4 \%)$. A battery of tests from the World Health Organisation Neurobehavioural Core Test Battery and the Grooved Peg Board (GPP) test (an additional test for motor dexterity) were used to assess the neurobehavioural functions. ${ }^{6}$

Workers with ALADl-1 genotype had significantly higher mean ALAU $(0.86 \mathrm{mg} / \mathrm{g}$ creatinine) compared to workers with ALAD 1-2/2-2 genotypes $(0.61 \mathrm{mg} / \mathrm{g}$ creatinine), even after correcting for possible confounders. No significant differences were noted for mean blood lead and haemoglobin levels for both the groups. ALAD1-2/2-2 genotype workers had significantly better results compared to ALADl genotypes in the mean GPP preferred hand (55.5 seconds $v$ 62.6 seconds; $\mathrm{p}<0.01)$, GPP non-preferred hand $(60.3$ seconds $v 67.7$ seconds; $\mathrm{p}<0.05)$, and mean GPP scores for preferred and non-preferred hands ( 57.9 seconds $v 65.4$ seconds; $\mathrm{p}<0.001$ ) tests.

These two groups of workers had similar lead exposure as measured by their blood lead levels (ALAD1-1 $v$ ALAD1-2/2-2; $21.3 \mu \mathrm{g}$ dl $v 22.7 \mu \mathrm{g} / \mathrm{dl}$, respectively). Although there were no significant differences between the mean blood lead levels for the two groups, workers with ALADl-l genotypes had significantly higher ALAU compared to those with ALADI-2/2-2 genotypes. It could be that, given the same amount of lead exposure, ALAD2 alleles are more resilient to the effects of lead as reflected in a lower concentration of ALAU.
Several lines of evidence have suggested that $\delta$-aminolevulinic acid (ALA) is the neuropathological agent in lead poisoning. In vitro studies have shown the neurotoxicity of ALA. Clinical manifestations of lead poisoning closely resemble those of the acute neurological attacks in the hepatic porphyrias, during which the levels of ALA and porphobilinogen are significantly increased. The role of ALA accumulation in lead poisoning is supported by the report that asymptomatic heterozygotes for the ALAD deficient porphyria are prone to acute lead poisoning when exposed to low levels of lead. Lead is known to inhibit ALAD which results in the build up of ALA, detectable in the plasma and urine at blood lead levels less than $10 \mu \mathrm{g} / \mathrm{dl}$. Aminolevulinic acid resembles $\gamma$-aminobutyric acid receptors in the nervous system; this is thought to be one of the primary mechanisms of lead induced neurotoxicity.

Bellinger et al studied 79 subjects (aged 19 or 20 years) using a battery of neuropsychological tests. Sixty seven of the subjects had ALAD1-1 phenotypes, while five had ALAD12. On "nearly every endpoint" of the neuropsychological test, the five individuals with the ALAD2 phenotype had better scores compared to 67 subjects with ALADl, even after adjustment for dentin lead levels. ${ }^{5}$ Our subjects with ALADl-2/ALAD-2 genotypes also did significantly better in one of the neurobehavioural tests compared to subjects with ALAD1-1 genotype.

In summary, workers with ALADl-1 genotypes have significantly higher ALAU and had significantly poorer neurobehavioural scores involving motor dexterity (GPP) compared with workers with ALADl-2/2-2 genotypes. The ALAD2 allele may exert certain protective measures against the neurotoxic effects of lead as shown by lower ALAU levels among workers with the ALAD2 allele. This hypothesis is preliminary given the small sample size of the group with ALADl-2/2-2 genotypes. Further study involving a larger cohort of workers with ALAD2 allele would be needed to confirm this.

S-E Chia, E Yap, K-S Chia

Department of Community, Occupational \& Family Medicine (MD3), Faculty of Medicine, National University of Singapore, 16, Medical Drive, Singapore 117597, Republic of Singapore; cofcse@nus.edu.sg

doi: 10.1136/oem.2004.012898

\section{References}

1 Kelada SN, Shelton E, Kaufmann RB, et al. $\delta$ Aminolevulinic acid dehydratase genotype and lead toxicity: a HuGE review. Am J Epidemiol $2001 ; 154: 1-13$.

2 Onalaja AO, Claudio L. Genetic susceptibility to lead poisoning. Environ Health Perspect 2000; 108(suppl 1):23-8

3 Goodman M, LaVerda N, Clarke C, et al. Neurobehavioural testing in workers occupationally exposed to lead: systematic review and meta-analysis of publications. Occup Environ Med 2002;59:217-23.

4 Seeber A, Meyer-Baron M, Schaper M. A summary of two meta-analyses on neurobehavioural effects due to occupational lead exposure. Arch Toxicol 2002:76:137-45.
5 Bellinger D, Hu H, Titlebaum L, et al. Attentional correlates of dentin and bone lead levels in adolescents. Arch Environ Health 1994:49:98-105.

6 Chia SE, Chia HP, Ong CN, et al. Cumulative blood lead levels and neurobehavioral test performance. Neurotoxicology

1997; 18:793-804.

\section{BOOK REVIEWS}

\section{$A B C$ of occupational and} environmental medicine, 2 nd edition

Edited by David Snashall and Dipti Patel (pp vii $+124, £ 19.95), 2003$. London: BMJ Books.

What is an ABC? I think it is usually taken to be a simple introductory text, suitable for those contemplating learning more about the subject, and therefore I read this book with the needs of such people in mind. They might be medical students, general practitioners or non-medical occupational health trainees, the sort of people I have taught over the years. How far does it go towards serving this purpose?

No fewer than 21 people have contributed, which must be close to a record for such a short book. This means that most of the chapters are written by people who have extensive practical knowledge of their subjects, and the editors have made a good effort to see that the specialist contributors have covered the occupational medical issues and vice versa. The format is of brief textual descriptions supplemented by many tables, boxes, and illustrations. This does not make for fluent reading since these interrupt each other to fit the size of the page rather than the logic of the argument. The 20 chapters vary in length and detail but are up-to-date and accurate in the facts provided; the tables in particular are a fund of useful information. However, the level of information does vary and some chapters serve the prospective reader very well as an introduction while others will bewilder with detail. In terms of an interesting read (which in my old fashioned way I always hope for in a book), the last four chapters on genetic and environmental matters are the most thought provoking. The lists of recommendations for further reading, including a good number of websites, are useful.

In my view it does not serve as an introduction to the subject, which purpose requires more explanation and less information. I think a tyro reading it would not really get a balanced understanding of what the practice of occupational and environmental medicine is about, and might even find it a bit daunting. It does however have plenty in it for a postgraduate revising for examinations (but does not replace more detailed textbooks), and such trainees will certainly find it useful, as will most specialists for a bit of personal CMD. And I shall also find the tables and references useful for the next few years. For the price, it is good value for anyone training in or practising occupational medicine.

A Seaton 


\section{The particulate air pollution controversy: a case study and lessons learned}

Robert F. Phalen (£43.00), 2002. Dordrecht: KB. ISBN 1402072252

Confused about particles? Read this book! The past 15 years have seen an explosion in interest in and concerns about the effects of ambient particles on health. Huge sums have been spent on research and journals are dominated by papers ranging from cutting edge epidemiology to molecular biology. Something for everybody-certainly-and no solution yet in sight.

Robert Phalen has tried to bring order to the field by producing a short book setting out what is known, what is unknown, and what are the lessons that should have been learnt. The factual content will be familiar to those in the field though many who comment on the field would do well to read this book closely. More important than the review of what we know are the author's critiques of ill-founded inferences allegedly based on the evidence. The reader is stimulated by this and should recall: evidence is not proof, and hypotheses are not facts. Because the topic is important and because reducing levels of pollutants is becoming expensive and may involve actions that may affect health negatively, we need to be exacting in our requirements for proof of effects and proof of benefits. But how does all this fit in with the Precautionary Principle? This is not discussed and is a lapse on the part of the author. It may be that the US-centric approach that the author has adopted is responsible. European (including UK!) thinking about the Precautionary Principle is developing rapidly though this cannot be discussed here.

The author asks important questions about low dose affects, hormesis, and the overall costs and benefits of lowering levels of particles. Many will find areas for disagreement: all should be stimulated!
At $£ 43.00$ for a small book, this is not a cheap read but it is important.

R L Maynard

\section{Dioxins and health, 2nd edition}

Edited by Arnold Schecter and Thomas A Gasiewicz (pp 952, £96.95), 2003, Hoboken, NJ: John Wiley \& Sons. ISBN 0 471433551

The second edition of this book is published seven years after the first, in which time the science of dioxins and related compounds has moved on (related compounds are those whose action also appears to be mediated via binding to a cellular protein called the Ah receptor). The book reflects the progress in the field, with several new chapters on the Ah receptor, and a marked emphasis on new information on the molecular biology of dioxins in the updates of existing chapters. These cover all relevant areas of toxicology and epidemiology, as well as sources, distribution, and risk assessment.

It is important to note that this is not a textbook. It is a collection of chapters written by some of the leading researchers in the field and it reflects the detailed knowledge that these individuals have in their own areas. For example, the chapter on the immunotoxicology of dioxins opens with a clear introductory text on the basics of the immune system but progresses quickly to a discussion of complex immunology and virus infection models. The target audience which, according to the editors, includes "well-educated and intelligent lay persons" will struggle with much of this. However, other chapters are more readable. There are good and extensive reviews of the animal carcinogenicity and reproductive toxicity data on dioxins. I particularly enjoyed the chapter on reproductive epidemiology which had a good summary and where the authors had assessed the data against the Bradford-Hill criteria to test the strength of evidence for effects of dioxins on the human reproductive system. Of particular interest to the general reader might be the chapter on the Seveso accident of 1976, which has been revised to include a discussion of the result of the 20 year mortality study on the exposed population.

The book has few other problems. It is repetitive with several chapters overlapping in content. In places it is not up-to-date. For example, the discussion of risk assessment in the overview lacks any mention of the key 2001 risk assessments by the WHO Joint Expert Committee on Food Additives (JECFA) and the European Union's Scientific Committee for Food (SCF) which were both based on the developmental effects of dioxin rather than its carcinogenicity, the basis of earlier risk assessments. Nevertheless, it fills a gap in the market and would be a valuable source for a biomedical professional interested in learning more about these fascinating chemicals.

F D Pollitt

\section{CORRECTION}

doi: 10.1136/oem.2003.008680corrl

All-cause and cause specific mortality in a cohort of 20000 construction workers; results from a 10 year follow up. V Arndt, D Rothenbacher, U Daniel, et al. Occup Environ Med 2004;61:419-25.

The second point in the main messages box (page 420) should read:

"Excess mortality was observed for pneumoconiosis (SMR 2.30) and for non-transport accidents such as falls (SMR 1.87) and being struck by falling objects (SMR 1.90)."

The authors deeply regret this typographical error and point out that none of the conclusions of the article is altered by this correction. 